\title{
Utilizing a health-promotion model to predict self-care adherence in patients undergoing coronary angioplasty in Bushehr, Iran
}

This article was published in the following Dove Press journal:

Patient Preference and Adherence

\author{
Azime Khodaminasab' \\ Mahnoush Reisi' \\ Hakime Vahedparast ${ }^{2}$ \\ Rahim Tahmasebi ${ }^{3}$ \\ Homamodin Javadzade \\ 'Department of Health Education \\ and Health Promotion, Bushehr \\ University of Medical Sciences, \\ Bushehr, Iran; ${ }^{2}$ Department of Medical \\ Surgical Nursing, Bushehr University \\ of Medical Sciences, Bushehr, Iran; \\ ${ }^{3}$ Department of Biostatistics, Bushehr \\ University of Medical Sciences, \\ Bushehr, Iran
}

\begin{abstract}
Background: Self-care refers to the conscious actions and behaviors that patients engage in to maintain and promote their own health and to the decisions that they make about managing signs or symptoms. Despite the importance of self-care in improving the health status of patients with cardiovascular disease, such as those undergoing angioplasty, these patients do not implement self-care optimally. This study aimed to identify factors affecting self-care behaviors in cardiac patients undergoing angioplasty based on a health-promotion model.
\end{abstract}

Methods: A cross-sectional study was conducted among 200 cardiovascular patients undergoing angioplasty referred to the Bushehr Health Center. Health-promotion-model constructs and self-care behaviors were assessed by a researcher-made questionnaire. Data were analyzed by SPSS version 22 using multiple linear regression analyses.

Results: Stepwise regression revealed that three variables - perceived barriers, perceived self-efficacy, and social support - were significant predictors of self-care behaviors among patients undergoing angioplasty. These factors accounted for $43.1 \%\left(R_{2}=0.431\right)$ of variance in self-care. Among the health-promotion-model constructs, self-efficacy $(\beta=0.237, P<0.001)$ was the strongest predictor of self-care behaviors, followed by perceived barriers $(\beta=-0.195$, $P<0.001)$ and perceived social support $(\beta=0.13, P<0.001)$. Perceived benefits did not significantly predict self-care behaviors.

Conclusion: According to the results of this study, it is suggested that designing and implementing training programs to improve self-efficacy and perceived social support of cardiovascular patients and also decreasing barriers to self-care may improve self-care behaviors among patients undergoing angioplasty.

Keywords: self-care adherence, health-promotion model, coronary angioplasty

\section{Introduction}

Cardiovascular disease is one of the major causes of mortality and disability worldwide and is becoming the leading cause of death or disability in most countries now. These diseases cause the deaths of 12 million people around the world every year. By the year 2020, at least one of three deaths in developed countries will be due to cardiovascular disease. ${ }^{1,2}$ Cardiovascular disease causes $43 \%$ of deaths among Iranian people, according to a World Health Organization (WHO) report in $2018 .{ }^{3}$

Coronary artery disease is one of the most important cardiovascular diseases, with rising mortality rates in the world as well as in Iran with an incidence rate of 181 . Per 100 thousand people. ${ }^{4}$ Even though the deaths from coronary artery disease occurs over the age of 70 in developed countries, this disease is the first cause of death over the age of 35 in Iran. ${ }^{5}$ Uncontrolled coronary artery disease can lead to numerous
Correspondence: Homamodin Javadzade Department of Health Education and Health Promotion, Bushehr University of Medical Sciences, Bushehr, Iran Tel +98 9|3 02| 607|

Email sh.javadzadeh@bpums.ac.ir 
complications, such as heart failure, angina, and physical disabilities. It also causes irreparable irregularities in other organs of the body (eg, kidney, digestive system, liver) and affects patients' quality of life severely. ${ }^{6}$

One therapy for coronary artery disease is percutaneous coronary intervention, which involves transluminal coronary angioplasty and stenting of the coronary arteries. This method is one of the most important achievements of medical science, and as a novel and unrivaled method for the treatment of many patients with coronary artery disease has replaced coronary artery-bypass graft surgery. ${ }^{7}$ This technique has now changed the face of cardiovascular care as an economical and less aggressive and invasive approach compared to onset surgery, and many patients worldwide are undergoing this intervention. ${ }^{8}$ Coronary angioplasty can help reduce or eliminate symptoms and improve the patient's condition by opening narrowed vessels. ${ }^{4}$

In Iran, patients undergoing angioplasty are admitted 1 day before and kept 1-2 days after the procedure and then discharged. This limited time causes clinicians, especially nurses, to have less time to assess patients' diverse needs, understand patients' experiences, and help them to adapt to their new situation. Also, this early-discharge process causes anxiety and inability among patients to meet their own health needs at home. Consequently, $30 \%-40 \%$ of patients undergoing angioplasty, face recurrent angina, recurrent myocardial infarction, death, or recurrence of the procedure in the 2 years postoperation. However, a significant number of relapses and complications of the disease can be reduced and prevented with proper self-care and necessary care. ${ }^{9}$

Learning self-care skills has always been one of the key points in chronic-disease-management programs. ${ }^{10}$ Self-care refers to the conscious actions and behaviors in which patients engage to maintain and promote their own health, and to the decisions they make about managing signs or symptoms. ${ }^{11}$ Adherence to self-care behaviors prevents the exacerbation of symptoms of the disease, creates a greater sense of health in patients, and reduces the number of hospital admissions, mortality, and the cost of their treatment. ${ }^{12}$

Despite the importance of self-care in improving the health status of people with cardiovascular disease, the results of studies indicate that self-care in these patients is not desirable. In this regard, the results of a comprehensive study that assessed the status of self-care in cardiovascular patients in 15 countries around the world showed that selfcare in these patients was not favorable and thus this situation was considered a global challenge and required a plan and worldwide action. ${ }^{13}$ In research by Heo et al, most patients with heart disease did not have acceptable or sustainable selfcare behavior. ${ }^{14}$ In Moadab et al's research, $>90 \%$ of patients with cardiovascular disease did not have desirable self-care. ${ }^{15}$

It seems that the key to self-care is acceptance of responsibility and participation of the patient to control numerous outcomes and complications of the disease by properly managing behavior. ${ }^{16}$ Participation in self-care in cardiovascular patients can be influenced by several factors that have always been of interest to researchers.

Various studies suggest that self-care behaviors are influenced by demographic and modifiable psychological variables. Information about factors that affect self-care behaviors in patients undergoing angioplasty based on a theoretical framework is scarce. In this study, a healthpromotion model (HPM) was used to explain factors related to self-care behaviors of patients undergoing angioplasty. The HPM is one of the most comprehensive and predictive models providing a theoretical framework for discovering effective factors in health-promoting behavior. This HPM includes three groups of factors: individual characteristics and experiences, behavior-specific cognition and affect, and situational/interpersonal influences (such as social support, situational influences, commitment toward the behavior, preferences, and immediate competitors). The category of behavior-specific cognition and affect includes perceived barriers (person's perception of the difficulties and cost of performing behaviors), perceived benefits (belief in usefulness of perceived action to reduce the risk of disease and understanding of the health benefits), self-efficacy (people's judgments of their capabilities to execute given level of performance), and affect related to the behavior. Most HPM research has focused on these components to date. ${ }^{17-20}$

Constructs of the model, including prior related behavior perceived health status, perceived benefits, perceived barriers, perceived self-efficacy, and social support, were effective in explaining behavior in more than $50 \%$ of the studies. ${ }^{21}$ Pender's HPM is one of the all-inclusive and useful methods to study self-care behaviors and is also a framework for exploring the factors affecting these behaviors. ${ }^{22}$ This model has been employed in many studies and its effectiveness confirmed. ${ }^{17-19}$

Finally, due to the importance of self-care behaviors in cardiovascular patients undergoing angioplasty and the undesirably low adherence of self-care behaviors, besides the limited exact information on factors affecting self-care status in these patients, the aim of this study was to identify factors affecting self-care behaviors in cardiac patients undergoing angioplasty based on this HPM. The results of 
this study can be used as guidance in designing educational interventions to enhance self-care in cardiac patients treated with angioplasty.

\section{Methods}

This cross-sectional study was conducted on 200 cardiovascular patients undergoing angioplasty referred to the Bushehr Health Center. This study was approved by the ethics committee of Bushehr University of Medical Sciences (IR.BPUMS.REC.1396.56). At first, a list of patients who had been subjected to angioplasty in the first 6 months of 2017 was taken from the medical records department of Bushehr Heart Center. Next, a phone call was made to patients who met the entry criteria, and after an introduction of the purpose of the present study, they were invited to complete research questionnaires. Among those who were called by telephone, 55 did not answer or were a wrong number, six had died, and 25 did not agree to enter the study. The inclusion criteria for the study were $\geq 18$ years of age, Persian-speaking, having coronary artery disease, treated with angioplasty (due to angina, acute coronary syndrome, or myocardial infarction) at least 1 month prior, lack cognitive problems based on their medical records, not working as a health care professional, and eventually being willing to participate in the research. The exclusion criterion was partial completion of the questionnaire. The study was conducted in accordance with the Declaration of Helsinki.

The interviewer first explained the purpose of the survey, the participant's rights, the risk and benefit of participation, and the plan to protect the confidentiality of participant information. Further, written informed consent was obtained prior to the interview. Then, for patients who had given consent to participate in the study, the HPM and self-care behavior questionnaire were completed. The completion of the selfreport questionnaires in this study took 30-45 minutes for each patient.

\section{Measurement}

\section{Health-promotion-model constructs}

To assess the constructs of HPM, a researcher-made questionnaire was used. Items were developed for measuring perceived benefits, perceived barriers, self-efficacy, and social support constructs focused specifically on self-care behaviors in patients undergoing angioplasty. This questionnaire consisted of 46 items with 5-point Likert answers from completely disagree (1) to completely agree (5) (nine items for perceived benefits, 19 items for perceived barriers, 12 items for perceived social support, and eleven items for perceived self-efficacy). To obtain scores for each subscale, item scores in each subscale were summed and divided by the number of constituent items. Scores were recoded for perceived barriers for negatively worded items, and mean scores were calculated for each scale. Higher scores indicated higher perceived benefits, lower perceived barriers, higher self-efficacy, and higher perceived social support.

In order to provide research tools, a comprehensive search was conducted in library and online resources for existing tools for measures of self-care of cardiovascular patients. The primary version of the design based on the collected information consisted of 93 items. In the next step, seven experienced people consisting of two health-education specialists, three nursing doctors, and two qualified nursing staff of the Cardiac Intensive Care Unit discussed each item in the questionnaire. Then, an expert panel of 13 was convened to review the questionnaire items to detect and resolve any inadequate terms or concepts. The expert panel was comprised of faculty members of health-education and -promotion and nursing departments and a hospital nurse educator for cardiovascular patients. To quantify the extent of expert agreement, we used the content-validity index (CVI). The experts were asked to evaluate each item for simplicity, relevance, and clarity using a 4-point Likert-type scale, with 1 being a low score and 4 a high score. For items rated 1 , we asked the expert who provided this rating to give his or her suggestions for modifying it. In content validity, changing the format of questions and omitting irrelevant questions were performed. Then, the CVI was calculated as 0.89 . A content-validity ratio (CVR) was also applied to assess the extent of the experts' agreement on the questions through a three-response categorized Likert-type scale as "necessary", "useful but not necessary", and "unnecessary" for each item. If an item was rated unnecessary, the expert who rated thus was asked to provide his/her suggestions for its modification or elimination. In this study, a CVR score of $\geq 0.54$ indicated good content validity. ${ }^{22}$ The CVR for the tool was calculated as 0.76 .

The construct validity of the questionnaire was tested using principal-component factor analysis with quartimax rotation. The Kaiser-Meyer-Olkin measure was 0.81, indicating that sampling was adequate for the factor analysis. Analysis of data extracted five components that explained $70.1 \%$ of the total variance among the scale items. The structure of the components obtained for 79 items was almost the same as the original structure of the questionnaire. Finally, the reliability of the scale was calculated in a pilot study conducted using a convenience sample of 30 patients undergoing 
coronary angioplasty by Cronbach's $\alpha$, and results were $0.71,0.81,0.84$, and 0.90 for perceived benefits, perceived barriers, perceived self-efficacy, and perceived social support, respectively.

\section{Self-care behavior}

This is a 21-item scale that examines the level of self-care behaviors in patients undergoing angioplasty in the domains of diet (six items), physical activity (six items), treatment adherence (six items), stress management (two items), and smoking (one item). Each item was rated from 0 (never) to 4 (always). To obtain scores for each subscale, item scores were summed and divided by the number of constituent items. Mean scores were calculated for each subscale (0-4). Higher scores indicated higher levels of self-care. The CVI and CVR of the questionnaire were calculated as 0.87 and 0.94 , respectively. The scale showed adequate internal consistency $(\alpha=0.72)$.

\section{Sociodemographic characteristics}

Sociodemographic attributes included age, sex, marital status, education level, employment status, income, history of the disease, family history of heart disease, and frequency of angioplasty. Levels of education were divided into four categories: illiterate, primary school (1-5 years of schooling), secondary/high school (6-12 years of schooling), and education above high school.

\section{Data analyses}

Independent-sample $t$-test, ANOVA, and $\chi^{2}$ tests were used to examine main dependent outcomes among characteristics of the sample. Correlation analysis was used to determine associations between self-care behavior and model constructs. Multiple linear regression analysis for variable selection was used to determine predictive HPM constructs. All statistical analyses were performed using SPSS version 22.0. In all tests, level of significance was considered at the 0.05 level.

\section{Results}

\section{Sample characteristics}

In this study, the mean age of participants was $58.77 \pm 10.21$ years. More than half the participants $(59.5 \%)$ were male, most $(87.5 \%)$ were married, $42 \%$ were unemployed, and about a third (33.5\%) had little educated (elementary). More than half $(59.5 \%)$ had a history of some chronic diseases (28\% diabetes, high cholesterol 31\%, high blood pressure $22.5 \%$, chronic kidney disease $8 \%$, thyroid $1.5 \%$ ), 38.5\% had a family history of heart diseases, and $74 \%$ had undergone angioplasty only once. The results showed that self-care behaviors were significantly associated with educational level ( $t=4.85, P=0.003)$ and employment status $(t=2.25$, $P=0.025)$. Participants who were employed and had higher education showed a better self-care behavior than others. Other demographic characteristics did not achieve statistical significance (Table 1).

Study findings revealed that the mean of total scores for self-care behaviors was $2.25 \pm 0.39$ (possible range $0-4$ ). The highest through lowest mean scores were seen consecutively in nonsmoking $(2.76 \pm 0.972)$, healthy diet $(2.72 \pm 0.431)$, treatment adherence $(2.33 \pm 0.546)$, stress management (1.86 \pm 0.667$)$, and physical activity (1.71 \pm 0.659$)$ (Table 2$)$. Proportionally, $28.5 \%$ of patients ceased physical activity due to symptoms such as shortness of breath and chest pain, and $47 \%$ of those sexually active were aware of sexual health practices and stopped their sexual activity when they had shortness of breath and chest pain. Only $13 \%$ of the patients avoided salty food frequently or always, replacing salt with citrus or lemon juice, $89.5 \%$ often or always avoided using saturated fat or high-fat dairy products, $90 \%$ took their medications on a regular basis and on the instructions of the physician, $80 \%$ went to their doctor on a timely basis to track their treatment status, and 14\% used stress- and anxietycontrol methods. Overall, 19\% of patients were smokers (cigarettes or hookahs), 11.5\% used to smoke cigarettes, and a small proportion $(7.5 \%)$ used to smoke a hookah regularly.

Means for HPM constructs related to self-care behaviors were $3.89 \pm 0.37$ for perceived benefits, $2.63 \pm 0.45$ for perceived barriers, $3.45 \pm 0.59$ for perceived self-efficacy, and $2.15 \pm 0.73$ for perceived social support (Table 3 ).

Pearson correlation coefficients of HPM constructs and self-care behaviors are presented in Table 4. There was a significant correlation between self-care behaviors and perceived self-efficacy $(r=0.57, P<0.001)$, perceived benefits $(r=0.321, P<0.001)$, perceived barriers $(r=-0.452$, $P<0.001)$, and perceived social support $(r=0.402, P<0.001)$.

Multiple linear regression analysis was conducted to specify the HPM constructs that significantly predicted self-care behaviors. After examination of the assumption of multiple linear regression, independent variables, including perceived benefit, perceived barriers, perceived self-efficacy, and perceived social support were entered into the multiple linear regression model simultaneously. The model revealed that three variables - perceived barriers, perceived selfefficacy, and social support - were significant predictors of self-care behaviors among patients undergoing angioplasty. These psychological factors accounted for $43.1 \%\left(R^{2}=0.431\right)$ 
Table I Differences among demographics and self-care behaviors $(n=200)$

\begin{tabular}{|c|c|c|c|c|}
\hline & $\begin{array}{l}\text { Mean } \pm \text { SD (range) } \\
\text { n (\%) }\end{array}$ & $\begin{array}{l}\text { Self-care behaviors, } \\
\text { mean } \pm \text { SD }\end{array}$ & $t(F)$ & $P$-value \\
\hline Age, years & $58.77 \pm 10.21(32-90)$ & & 81.332 & $0.000 *$ \\
\hline \multicolumn{3}{|l|}{ Sex } & \multirow[t]{3}{*}{1.751} & \multirow[t]{3}{*}{$0.08 I^{* *}$} \\
\hline Male & $119(59.5 \%)$ & $2.292 \pm 0.396$ & & \\
\hline Female & 81 (40.5\%) & $2.194 \pm 0.378$ & & \\
\hline \multicolumn{3}{|l|}{ Marital status } & \multirow[t]{3}{*}{-0.0362} & \multirow[t]{3}{*}{$0.718^{* *}$} \\
\hline Married & $175(87.5 \%)$ & $2.256 \pm 0.375$ & & \\
\hline Unmarried & $25(12.5 \%)$ & $2.226 \pm 0.498$ & & \\
\hline \multicolumn{5}{|l|}{ Educational level } \\
\hline Illiterate & $47(23.5 \%)$ & $2.076 \pm 0.335$ & \multirow[t]{4}{*}{4.856} & \multirow[t]{4}{*}{$0.003^{* * * *}$} \\
\hline Primary school & $67(33.5 \%)$ & $2.232 \pm 0.348$ & & \\
\hline Secondary/high school & $63(31.5 \%)$ & $2.27 I \pm 0.460$ & & \\
\hline Above high school & $23(11.5 \%)$ & $2.345 \pm 0.422$ & & \\
\hline \multicolumn{3}{|l|}{ Employment status } & \multirow[t]{3}{*}{-2.25} & \multirow[t]{3}{*}{$0.025^{* *}$} \\
\hline Employed & $68(34 \%)$ & $2.219 \pm 0.386$ & & \\
\hline Unemployed & $132(66 \%)$ & $2.359 \pm 0.470$ & & \\
\hline \multicolumn{3}{|l|}{ History of disease } & \multirow[t]{3}{*}{-0.005} & \multirow[t]{3}{*}{$0.996 * *$} \\
\hline Yes & $119(59.5 \%)$ & $2.252 \pm 0.402$ & & \\
\hline No & 81 (40.5\%) & $2.253 \pm 0.378$ & & \\
\hline \multicolumn{3}{|c|}{ Family history of heart disease } & \multirow[t]{3}{*}{0.235} & \multirow[t]{3}{*}{$0.814 * *$} \\
\hline Yes & 77 (38.5\%) & $2.26 I \pm 0.397$ & & \\
\hline No & $123(6 \mid .5 \%)$ & $2.247 \pm 0.389$ & & \\
\hline \multicolumn{3}{|l|}{ Income, IRR } & \multirow[t]{4}{*}{1.714} & \multirow[t]{4}{*}{$0.183^{* * * *}$} \\
\hline$<10,000,000$ & II 3 (56.5\%) & $2.219 \pm 0.435$ & & \\
\hline $10,000,000-15,000,000$ & $68(34 \%)$ & $2.332 \pm 0.418$ & & \\
\hline$>15,000,000$ & $19(9.5 \%)$ & $2.318 \pm 0.310$ & & \\
\hline \multicolumn{3}{|l|}{ Frequency of angioplasty } & \multirow[t]{3}{*}{-1.053} & \multirow[t]{3}{*}{$0.289 * *$} \\
\hline Once & $149(74.5)$ & $2.235 \pm 0.388$ & & \\
\hline More than once & $51(25.5)$ & $2.303 \pm 0.401$ & & \\
\hline
\end{tabular}

Notes: *One-sample $t$-test; ${ }^{*}$ independent-sample $t$-test; ${ }^{* * *}$ one-way ANOVA.

of variance in self-care. It means that patients with better self-efficacy and perceived social support and also those with low perceived barriers were more likely to exhibit better self-care behaviors. Among the HPM constructs, self-efficacy ( $\beta=0.237, P<0.001$ ) was the most powerful predictor of selfcare behaviors, followed by perceived barriers $(\beta=-0.195$,

Table 2 Self-care behavior domains ( $n=200)$

\begin{tabular}{|l|l|l|l|}
\hline & Mean & SD & Possible range \\
\hline Healthy diet & 2.72 & 0.431 & $0-4$ \\
Physical activity & 1.71 & 0.659 & \\
Treatment adherence & 2.33 & 0.546 & \\
Stress management & 1.86 & 0.667 & \\
Nonsmoking & 2.76 & 0.972 & \\
Total & 2.25 & 0.391 & \\
\hline
\end{tabular}

$P<0.001)$ and perceived social support $(\beta=0.13, P<0.001)$. It means that every additional point on the perceived selfefficacy and perceived social support scores was associated with 0.237 and 0.13 points in self-care behavior scores, respectively. Also, for every 1-point decrease in perceived barriers, there was a 0.195 -point increase in self-care behaviors (Table 5).

\section{Discussion}

Although self-care behaviors and lifestyle modification have clear benefits and are recommended for secondary prevention of coronary heart disease, especially patients undergoing angioplasty, most patients do not complete cardiac rehabilitation programs or engage in ongoing self-care behaviors. ${ }^{23}$ Therefore, the aim of this study was to determine factors 
Table 3 Health-promotion-model constructs $(n=200)$

\begin{tabular}{|l|l|l|l|l|}
\hline & Perceived benefits & Perceived barriers & Perceived self-efficacy & Perceived social support \\
\hline Mean & 3.89 & 2.63 & 3.45 & 2.15 \\
SD & 0.371 & 0.457 & 0.593 & 0.733 \\
Observed range & $1.88-5$ & $1.53-4.12$ & $1.82-5$ & $0.25-4$ \\
Possible range & $1-5$ & $1-5$ & $1-5$ & $1-5$ \\
\hline
\end{tabular}

related to self-care behaviors (as the most important way to control symptoms) and prevent complications among patients undergoing angioplasty based on HPM.

In the present study, the mean score for self-care behaviors was $2.25 \pm 0.391$ out of 4 . These results (based on mean values) indicated that participants in this study had a moderate level of self-care behavior. Concerning different domains of self-care, the results of this study showed that patient's adherence to self-care tasks was low in terms of physical activity and stress management and moderate regarding nonsmoking, healthy diet, and medication adherence.

Only $28.5 \%$ of patients had at least 30 minutes of physical activity on most days of the week. It seems that such factors as inappropriate weather conditions (hot and humid) at the place of research, older age, unwillingness to do solitary physical activity, fear of a recurrence, of disease and lack of centers for cardiac rehabilitation are possible reasons for this finding. In accordance with the results of this study, in other studies, most cardiac patients had a sedentary lifestyle. Lauck et al found that over half of these patients $(52.0 \%)$ had poor physical activity and lower than recommended. ${ }^{8}$ The majority of patients with cardiovascular disease $(96 \%)$ did not have regular physical activity in the study of Kamrani et al. ${ }^{24}$ These results are despite the fact that a meta-analysis on 48 studies revealed a decline in total and cardiovascular mortality by $20 \%$ and $26 \%$, respectively, as a result of exercise-training intervention in 8,940 myocardial infarction patients who had either experienced, undergone coronary revascularization, complained about angina pectoris, or had coronary artery disease documented by angiography. ${ }^{25}$ Therefore, the implementation of educational interventions to inform patients with coronary heart disease on the necessity of physical activity is essential.
Only $14 \%$ of patients in this study used stress- and anxiety-management methods, and according to the available evidence, most patients with cardiovascular disease experience high levels of stress and anxiety. In this regard, Bhattacharyya et al found that $65 \%-70 \%$ of patients with acute coronary syndrome experienced anxiety due to daily life and work experiences, and this stress and anxiety can have serious and unpleasant health outcomes for patients. ${ }^{26}$ Moser et al showed that cardiovascular patients with stress and anxiety are 4.9 times more likely to have recurrent infarction and experience mortality than other patients, due to recurrence of the disease. ${ }^{27}$ It seems that insufficient stress-management skills need more attention by physicians and health care providers, but instead seem to have been ignored by them.

Our study also showed that although adherence to some nutritional recommendations, such as consumption of lowfat foods instead of saturated-fat products, was favorable in most patients $(89.5 \%)$, only $13 \%$ of participants had a low-salt diet. The WHO suggests that every adult should consume $<5$ g of sodium each day. ${ }^{28}$ However, in Iran and most countries, the daily intake of salt per person is 9-12 $\mathrm{g}$ on average. ${ }^{29}$ Considering that according to the results of a qualitative study of cardiac patients, ${ }^{30}$ after recovering and passing the acute phase of the disease, patients gradually adapt to the family's dietary habits, as a result, a low-fat diet would be easier to follow than a low-salt diet for those using family food regimens. Patients can partially separate oil after cooking, but it is not possible to separate added salt from the food. On the other hand, it seems that patients and their families are less aware of the undesirable effects of salt intake than the consumption of fat for heart patients, and sometimes they do not even consider a low-salt regimen as

Table 4 Correlation matrix of health-promotion-model constructs and self-care behaviors $(n=200)$

\begin{tabular}{|l|l|l|l|l|l|}
\hline & Perceived benefits & Perceived barriers & Self-efficacy & Social support & Self-care \\
\hline Perceived benefits & $\mathrm{I}$ & & & & \\
Perceived barriers & -0.119 & $\mathrm{I}$ & $\mathrm{I}$ & & \\
Self-efficacy & $0.409^{\mathrm{a}}$ & $-0.44 \mathrm{I}^{\mathrm{a}}$ & $0.26 \mathrm{I}^{\mathrm{a}}$ & $\mathrm{I}$ & \\
Social support & 0.133 & $-0.215^{\mathrm{a}}$ & $0.570^{\mathrm{a}}$ & $0.402^{\mathrm{a}}$ & \\
Self-care & $0.32 \mathrm{I}^{\mathrm{a}}$ & $-0.452^{\mathrm{a}}$ & $\mathrm{I}$ & \\
\hline
\end{tabular}

Note: ${ }^{\text {aC }}$ orrelation significant at the 0.001 level (two-tailed). 
Table 5 Multiple linear regression analysis of health-promotionmodel constructs in predicting self-care behaviors $(n=200)$

\begin{tabular}{|l|l|l|l|l|}
\hline & SE & $\beta$ & $\boldsymbol{t}$ & $\boldsymbol{P}$-value \\
\hline Perceived benefits & 0.062 & 0.121 & 1.95 & 0.052 \\
Perceived barriers & 0.052 & -0.195 & -3.78 & 0.001 \\
Perceived self-efficacy & 0.043 & 0.237 & 5.46 & 0.001 \\
Perceived social support & 0.030 & 0.130 & 4.36 & 0.001 \\
\hline
\end{tabular}

Note: Coefficient of determination $R^{2}=0.431$.

a factor associated with improving their present condition. Therefore, in view of these cases, the results obtained in this study are justifiable. Thus, the implementation of health interventions to reduce the consumption of salt and follow a healthy diet in patients undergoing angioplasty is essential.

Adherence to the medication prescribed by the physician in $>90 \%$ of the patients of the present study was acceptable, and these patients always or most of the time had proper adherence to the drug regimen. In Lauck et al, 97\% of the subjects reported good compliance with medication regimens and oral antiplatelet therapy. ${ }^{8}$ Because for most patients, taking medication is the easiest and most important way to control the symptoms of the disease, it is likely that achieving these results was the result of this viewpoint in patients.

In this study, most of the patients refused to smoke. However, $19 \%$ of patients consumed tobacco (cigarette or hookah). Similarly to these results, Booth et al found that $15.4 \%$ of cardiovascular patients continued to smoke during the treatment period. ${ }^{23}$ Since adherence to this self-care behavior is very important, noncompliance with this behavior by even a small number of patients is not acceptable. Perhaps, one of the most important reasons for achieving these results is a lack of awareness and attention of these patients to smoking-abstinence strategies, which has been mentioned in qualitative research. ${ }^{30}$ Therefore, the implementation of educational interventions to inform patients about the hazards of smoking and ways to quit smoking can be effective in promoting this self-care component in these patients.

Other findings showed that adherence to self-care was weaker in patients with lower education and unemployed patients than in other patients. These results have also been reported in other studies. ${ }^{31-33}$ Therefore, paying special attention to these patients is essential in self-care-promotion programs. The other results of this study showed that although there was a positive and significant correlation between all constructs of HPM and self-care behaviors in the studied patients, only the three constructs of perceived self-efficacy, perceived barriers, and social support were predictors of self-care in these patients. These factors explained $43.1 \%$ of the variance in self-care behaviors in patients undergoing angioplasty. By contrast, perceived benefits as a construct of the HPM did not significantly predict self-care behaviors.

Perceived self-efficacy was identified as the strongest factor predicting self-care among patients undergoing angioplasty. This finding indicates that patients with a higher perception of self-efficacy had higher self-care scores. This particular finding in this study was consistent with the findings of a previous study in which self-efficacy was the strongest predictor of self-care behavior among South Korean patients after percutaneous coronary intervention. ${ }^{34}$ Increased self-efficacy is an effective factor in smoking cessation ${ }^{35}$ and healthy $\operatorname{diet}^{36}$ in patients with coronary artery disease. Since self-efficacy is the degree to which people believe they can perform specific behaviors or tasks to attain their set goals, cardiovascular patients with high levels of self-efficacy have a belief or certainty that they can perform or act on specific tasks of self-care and persist, even if they are facing other difficulties. Indeed, the ability of a person to engage in self-care is based on his or her level of self-efficacy. ${ }^{37}$ Consequently, increased confidence of cardiovascular patients undergoing angioplasty regarding selecting appropriate behaviors seems to improve adherence to self-care tasks. Self-efficacy is influenced by enactive mastery (performance expectations), vicarious experiences, verbal persuasion (verbal encouragement), and physiological and emotional feedback. ${ }^{38}$ Therefore, it is useful that educational interventions promote the patient's ability to perform self-care behaviors through self-efficacy strategies.

Our other findings add to the evidence that social support associated with better self-care behaviors among patients, consistent with existing literature. ${ }^{39-41}$ In countries like Iran, the family plays an important role in protecting and supporting patients, so this finding might be a result of this cultural factor. Similarly to our findings, Sayers et a ${ }^{41}$ identified perceived social support as a key factor in behavioral changes among patients with heart failure. They suggested that perceived social support was associated with relatively better self-reported medication and dietary adherence. As a result, low levels of support have a negative effect on treatment and self-care behaviors. If patients receive support, this accelerates the process of recovery, inhibits the recurrence of illness, eliminates negative side effects, and intensifies the effects of rehabilitation. Therefore, support becomes an additional force, besides natural forces, that serves to fight the illness, help recovery, or facilitate life with the illness.

Based on the results of this study, cardiac patients undergoing angioplasty who had lower barriers to self-care behaviors reported better compliance with self-care behaviors. Such findings are consistent with the results of a meta-analysis of health-related behaviors among South Koreans showing that 
a lower level of perceived barriers is the most important factor affecting behavior performance associated with improved health behaviors. ${ }^{42}$ The results of a qualitative study on patients at risk of cardiovascular disease also showed that perceived barriers to patient compliance with self-care behaviors played a key role in the prevention and control of cardiovascular disease. ${ }^{43}$ As such, these results suggest that health education can contribute to the development of strategies aimed at lowering barriers to performing self-care behaviors.

This study revealed that perceived benefits of self-care behaviors did not influence adhering to self-care behaviors in patients. A possible reason for this finding may be related to culture. In this regard, a qualitative study conducted in Iran reported that although most patients know about the benefits of self-care behaviors, such as healthy diet and exercise impact on level of blood sugar, lipids, blood pressure, weight control, and reducing health care costs, unfortunately, they do not follow the instructions. Indeed, most people in Iran would only engage in health-promoting behavior, such as self-care behaviors, after experiencing the worst condition. ${ }^{43}$ Therefore, the perceived benefit could not influence self-care behaviors in this study. This finding is supported by Larki et al, ${ }^{29}$ who determined that perceived benefits of recommended self-care were not a good predictor of self-care behavior among hypertensive patients.

Since this study was based on a convenience sample, its findings may not be generalizable to all Iranian patients undergoing angioplasty. This was a cross-sectional study, and conclusions about causality cannot be drawn. A longitudinal study that follows the study sample and reassesses their health outcomes later would help to discern the causal effects of HPM components. Self-care behaviors were evaluated with self-report, so the reliability of self-rated self-care behaviors may be subject to recall bias or memory failure.

\section{Conclusion}

There was both moderate and not good adherence to self-care behaviors among patients undergoing angioplasty. Unacceptable self-care is due to low perceived self-efficacy, low social support, and high perceived barriers. As such, it is necessary for health care providers to consider these factors in improving educational activities and communications with these patients to ensure a better effect on self-care behaviors. Patient education based on HPM constructs can be highly effective and will benefit patients.

\section{Acknowledgments}

This study was prepared as partial fulfillment for the degree of MSc in health education and was supported by Bushehr
University of Medical Sciences, Bushehr, Iran, and ethics code number IR.BPUMS.REC.1396.56. We are grateful to Bushehr Heart Center, Dr Marzieh Mahmoodi, Mahsa Reisi, and all others who willingly cooperated and participated in the study.

\section{Disclosure}

The authors report no conflicts of interest in this work.

\section{References}

1. Varaei S, Cheraghi M, Seyedfatemi N, Talebi M, Bahrani N, Dehghani A. Effect of peer education on anxiety in patients candidated for coronary artery bypass graft surgery: a randomized control trial. J Nurs Educ. 2013;2(3):28-37.

2. Nasiri A, Kazemi T. The impact of a planned educational program on patients' informational needs after heart valve replacement. Mod Care J. 2013;10(1):26-33.

3. World Health Organization. Noncommunicable diseases country profiles 2018. World Health Organization. Noncommunicable diseases country profiles 2018. Available from: https://www.who.int/nmh/countries/ 2018/irn_en.pdf?ua=1; 2018. Accessed September 14, 2018.

4. Parastoo R, Mohsen S, Mahin M, Hamid S. Evaluation of the effect of collaborative care on depression, anxiety and stress of patients after coronary angioplasty. Med Surg Nurs J. 2016;5(2):59-66.

5. Aghakhani N, Najafi Kalyani M, Salami J. The effect of discharge planning on self-catre ability in patients undergoing percutaneous transluminal coronary angioplasty in Seyedolshohada hospital, Urmia, 2014-2015. J Urmia Nurs Midwifery Fac. 2016;13(12):1029-1038.

6. Zeighami R, Alipour Heidari M. The effect of continuous care model on quality of life of patients after coronary angioplasty in Bou Ali Sina hospital. Evid Based Care. 2014;4(1):61-70.

7. Lin GA, Dudley RA, Redberg RF. Why physicians favor use of percutaneous coronary intervention to medical therapy: a focus group study. J Gen Intern Med. 2008;23(9):1458-1463.

8. Lauck S, Johnson JL, Ratner PA. Self-care behaviour and factors associated with patient outcomes following same-day discharge percutaneous coronary intervention. Eur J Cardiovasc Nurs. 2009;8(3):190-199.

9. Najafi Ghezeljeh T, Yadavar Nikravesh M, Emami A. Coronary heart disease patients transitioning to a normal life: perspectives and stages identified through a grounded theory approach. J Clin Nurs. 2014; 23(3-4):571-585.

10. Sharif F, Moshkelgosha F, Molazem Z, Najafi Kalyani M, Vossughi M. The effects of discharge plan on stress, anxiety and depression in patients undergoing percutaneous transluminal coronary angioplasty: a randomized controlled trial. Int J Community Based Nurs Midwifery. 2014; 2(2):60-68.

11. Riegel B, Lee CS, Dickson VV; Medscape. Self care in patients with chronic heart failure. Nat Rev Cardiol. 2011;8(11):644-654.

12. Lainscak M, Blue L, Clark AL, et al. Self-care management of heart failure: practical recommendations from the Patient Care Committee of the Heart Failure Association of the European Society of Cardiology. Eur J Heart Fail. 2011;13(2):115-126.

13. Jaarsma T, Strömberg A, Ben Gal T, et al. Comparison of self-care behaviors of heart failure patients in 15 countries worldwide. Patient Educ Couns. 2013;92(1):114-120.

14. Heo S, Moser DK, Lennie TA, Riegel B, Chung ML. Gender differences in and factors related to self-care behaviors: a cross-sectional, correlational study of patients with heart failure. Int J Nurs Stud. 2008; 45(12):1807-1815.

15. Moadab F, Ghanbari A, Salari A, Kazemnejad E, Sadaghi Sabet M, Pariad E. Study status of self-care behaviors and gender differences in patients with heart failure. J Payavard Salamat. 2014;8(3):220-234.

16. Luhr K, Holmefur M, Theander K, Eldh AC. Patient participation during and after a self-management programme in primary healthcare - The experience of patients with chronic obstructive pulmonary disease or chronic heart failure. Patient Educ Couns. 2018;101(6):1137-1142. 
17. Mohseni Pouya H, Majlessi F, Shojazadeh DS, Rahimi Foroushani A, Ghaffari R, Habibi V. Development and psychometrics of self-care assessment scale in heart surgery patients based on health promotion model. Razi Journal of Medical Sciences. 2016;23(150):11-19.

18. Ho AY, Berggren I, Dahlborg-Lyckhage E. Diabetes empowerment related to Pender's Health Promotion Model: a meta-synthesis. Nurs Health Sci. 2010;12(2):259-267.

19. Kamal Mirkarimi S, Maghsoudloo M, Berdi Ozouni-Davaji R, Raeisi V, Charkazi A, Raeisi M. The determinants of hypertension and commitment to implementing a nutrition program: application of Pender health promotion model. J Health Literacy. 2018;3(1):50-60.

20. Alkhalaileh MA, Bani Khaled MH, Baker OG, Khaled MH, Bond EA Pender's health promotion model: an integrative literature review. Middle East J Nurs. 2011;5(5):12-22.

21. Pender NJ, Murdaugh CL, Parsons MA, Ann M. Health promotion in nursing practice. 5 ed: Prentice Hall; 2006.

22. Lawshe CH. A quantitative approach to content validity. Pers Psychol. 1975;28(4):563-575.

23. Booth JN 3rd, Levitan EB, Brown TM, Farkouh ME, Safford MM, Muntner P. Effect of sustaining lifestyle modifications (nonsmoking, weight reduction, physical activity, and mediterranean diet) after healing of myocardial infarction, percutaneous intervention, or coronary bypass (from the Reasons for geographic and racial differences in stroke study). Am J Cardiol. 2014;113(12):1933-1940.

24. Kamrani AA, Foroughan M, Taraghi Z, et al. Self care behaviors among elderly with chronic heart failure and related factors. Pak J Biol Sci. 2014;17(11):1161-1169.

25. Taylor RS, Brown A, Ebrahim S, et al. Exercise-based rehabilitation for patients with coronary heart disease: systematic review and metaanalysis of randomized controlled trials. Am J Med. 2004;116(10): 682-692.

26. Bhattacharyya MR, Perkins-Porras L, Whitehead DL, Steptoe A. Psychological and clinical predictors of return to work after acute coronary syndrome. Eur Heart J. 2007;28(2):160-165.

27. Moser DK. "The rust of life": impact of anxiety on cardiac patients Am J Crit Care. 2007;16(4):361-369.

28. World Health Organization. A global brief on hypertension: Silent killer, global public health crisis. Available from: https://www.who. int/cardiovascular_diseases/publications/global_brief_hypertension/ en/; 2013. Accessed September 14, 2018.

29. Larki A, Tahmasebi R, Reisi M. Factors Predicting Self-Care Behaviors among Low Health Literacy Hypertensive Patients Based on Health Belief Model in Bushehr District, South of Iran. Int J Hypertens. 2018; 2018:1-7.
30. Vahedparast H, Mohammadi E, Ahmadi F; Department of Nursing, School of Medical Sciences, Tarbiat Modares University Tehran, Iran. The challenge of adherence from treatment-care regimens among patients with chronic diseases: a qualitative study. Iran South Med J. 2017;19(6):989-1004.

31. Seyam S, Hiedarnia A, Tavafian S. Self-caring behaviors among cardiac patients after coronary artery bypass graft surgery. J Guilan Univ Med Sci. 2011;20(79):31-39.

32. Vosoghi Karkezloo N, Mohammadnejad E, Namadi Vosooghi M, Akbari Kagi M, Abootalebi Daryasari G. Study of the self-care agency in patients with heart failure. Crit Care Nurs J. 2011;4(4):e7108.

33. Akyol AD, Çetinkaya Y, Bakan G, Yaralı S, Akkuş S. Self-care agency and factors related to this agency among patients with hypertension. J Clin Nurs. 2007;16(4):679-687.

34. Shin ES, Hwang SY, Jeong MH, Lee ES. Relationships of Factors Affecting Self-care Compliance in Acute Coronary Syndrome Patients Following Percutaneous Coronary Intervention. Asian Nurs Res (Korean Soc Nurs Sci). 2013;7(4):205-211.

35. Choi SH, Song KJ, Choi-Kwon S. Stages of change in smoking cessation and factors related to re-smoking after coronary artery bypass graft surgery. Taehan Kanho Hakhoe Chi. 2007;37(7):1159-1165. Korean.

36. Han SS, Lee JI, Kim YJ. Predicting factors on eating behavior in coronary artery disease patients. Taehan Kanho Hakhoe Chi. 2007;37(7): 1193-1201. Korean.

37. Parke H. Educational Intervention to Improve Self-Efficacy and SelfCare in Patients with Heart Failure. 2017.

38. Bandura A. Social Foundations of Thought and Action: A Social Cognitive Theory: Englewood Cliffs. NJ, US: Prentice-Hall, Inc; 1986.

39. Alizadeh Z, Ashktorab T, Nikravan Mofrad M, Zayeri F. Correlation between perceived social support and self-care behaviors among patients with heart failure. J Health Promot Manag. 2014;3(1):27-34.

40. Gallagher R, Luttik ML, Jaarsma T. Social support and self-care in heart failure. J Cardiovasc Nurs. 2011;26(6):439-445.

41. Sayers SL, Riegel B, Pawlowski S, Coyne JC, Samaha FF. Social support and self-care of patients with heart failure. Ann Behav Med. 2008; 35(1):70-79.

42. Jo H, Kim C, Lee H, Jeong H. A meta-analysis of health related behavior study based on health belief model in Korean. Korean J Health Psychol. 2004;9(1):69-84.

43. Sabzmakan L, Morowatisharifabad MA, Mohammadi E, et al. Behavioral determinants of cardiovascular diseases risk factors: A qualitative directed content analysis. ARYA Atheroscler. 2014;10(2):71-81.
Patient Preference and Adherence

\section{Publish your work in this journal}

Patient Preference and Adherence is an international, peer-reviewed, open access journal that focuses on the growing importance of patient preference and adherence throughout the therapeutic continuum. Patient satisfaction, acceptability, quality of life, compliance, persistence and their role in developing new therapeutic modalities and compounds to optimize

\section{Dovepress}

clinical outcomes for existing disease states are major areas of interest for the journal. This journal has been accepted for indexing on PubMed Central. The manuscript management system is completely online and includes a very quick and fair peer-review system, which is all easy to use. Visit http://www. dovepress.com/testimonials.php to read real quotes from published authors. 